\title{
Reduction Kinetics of Zinc Powder from Brass Converter Slag by Pyrometallurgical Method Using Hydrogen Gas ${ }^{\dagger}$
}

\author{
Tae-Hyuk Lee ${ }^{1}$, Sin-Hyeong Joo ${ }^{1}$, Hayk H. Nersisyan ${ }^{1,2}$, Man-Sik Kong ${ }^{3}$, \\ Jae-Woo Lee ${ }^{4}$, Ki-Won Park ${ }^{4}$ and Jong-Hyeon Lee ${ }^{1,2 *}$ \\ ${ }^{1}$ Department of Materials Science \& Engineering, Chungnam National University, Republic of Korea \\ ${ }^{2}$ Rapidly solidified Materials Research Center, Republic of Korea \\ ${ }^{3}$ Advanced Materials \& Processing Center, Institute for Advanced Engineering, Republic of Korea \\ ${ }^{4}$ Seowon Co., LTD, Republic of Korea
}

\begin{abstract}
A pyrometallurgical reduction process for the recovery of copper and zinc from brass secondary slag (BSS) was studied. Specifically, the effect of reduction temperature and time on the conversion to metallic phases was investigated. The brass secondary slag was characterized by X-ray diffraction, inductively coupled plasma-atomic emission spectrometry, automatic elemental analysis, thermogravimetric analysis, and field emission scanning electron microscopy. A two-step reduction of BSS was identified. The step 1 comprised the reduction of $\mathrm{ZnO}$, while the step 2 featured the reduction of $\mathrm{ZnO} \cdot \mathrm{Al}_{2} \mathrm{O}_{3}$. Furthermore, the application of a first-order reaction model with Arrhenius analysis, indicated a conversion of $\mathrm{ZnO}$ to $\mathrm{Zn}(\mathrm{g})$ that had a rate constant increasing from $1.4 \pm 0.13 \times 10^{-3} \mathrm{~s}^{-1}$ at $900{ }^{\circ} \mathrm{C}$ to $2.18 \pm 0.15 \times 10^{-2} \mathrm{~s}^{-1}$ at $1050{ }^{\circ} \mathrm{C}$. This reaction had an activation energy of $233.2 \pm 26.1 \mathrm{~kJ} / \mathrm{mol}$. Secondly, the conversion of $\mathrm{ZnO} \cdot \mathrm{Al}_{2} \mathrm{O}_{3}$ to $\mathrm{Zn}(\mathrm{g})$ and $\mathrm{Al}_{2} \mathrm{O}_{3}$ increased from $1.54 \pm 0.21 \times 10^{-5} \mathrm{~s}^{-1}$ at $900{ }^{\circ} \mathrm{C}$ to $1.09 \pm 0.19 \times 10^{-3} \mathrm{~s}^{-1}$ at $1050{ }^{\circ} \mathrm{C}$, and the activation energy was $376.7 \pm 22.4 \mathrm{~kJ} / \mathrm{mol}$. This reaction mechanism and its associated kinetic data can be applied to optimize the operation conditions of recycling processes for $\mathrm{Cu}$-containing wastes.
\end{abstract}

Keywords: pyrometallurgy, copper converter slag, kinetic analysis, zinc powder

\section{Introduction}

Copper and zinc are important base metals required for various applications in metallurgical and chemical industries. The annual global output of copper and alloy products represents around 16.1 million tons, of which about 15.3 million tons (75-80\%) originate from refined copper, while about 4.2 million tons (20-25\%) are derived from direct melt scrap (Moskalyk P.R. and Alfantazi A.M., 2003).

However, the increasing worldwide demand for zinc and copper has necessitated intensive studies into the recovery and extraction of these metals from different sources (Rudnik E. et al., 2009). Some of these metals are

Received 27 May 2015 Accepted 14 July 2015

J-STAGE Advance published online 5 August 2015

1,2 99 Daehak-ro, Yuseong-gu, Daejeon, Republic of Korea

51 Goan-ro, Baekam-myeon, Cheoan-gu, Yongin, Republic of Korea

4 6B-15 Banwol Ind. \#402-1 Moknae-dong, Danwon-gu, Ansan, Kyunggi-do, Republic of Korea

* Corresponding author: Jong-Hyeon Lee;

E-mail: jonglee@cnu.ac.kr

TEL: +82-42-821-6596 FAX: +82-42-822-5850 recovered from different secondary slags, e.g., brass dross, brass ash, and flue dusts in electric furnaces. These brass secondary slags (BSS) are by-products obtained during brass scrap smelting and crushing of brass slag. It has been estimated that for every tons of copper production about 2.2 tons of slag are generated, so that 24.6 million tons of slag result from world copper production every year (Gorai B. et al., 2003).

BSS usually contains $\mathrm{Cu}, \mathrm{Zn}$, and other minor elements such as $\mathrm{Pb}, \mathrm{Fe}, \mathrm{Ni}, \mathrm{Si}$, and $\mathrm{Sb}$ (Jha M.K. et al., 2001). However, these slags contain different level of impurities depending on source. Recovery and extraction of these metals is necessary and important from both economic and environmental viewpoints.

In industries, various methods are used to extract metals from BSS. One of these, the hydrometallurgical process, is used to recover and recycle metals from BSS using different leaching agents, including sulfuric acid (Anand S. et al., 1983), hydrochloric acid (Sharma K.D. and Row B.R.L., 1985), cyanide (Anand S. et al., 1980) acetic acid (Altundogan H.S. and Tumen F., 1997), and ammonia (Sukla L.B. et al., 1986). However, the use of leaching agents is harmful to the human body and can cause environmental pollution. 
The dra drawbacks can be overcome using pyromotallurgical smelting to recover $\mathrm{Cu}$ and $\mathrm{Zn}$ from BSS. The top submerged lance (TSL) process is a typical pyro-metallurgy method that was commercialized and researched to improve recovery efficiency. The TSL process provides highly efficient mixing and a heat source for reaction, due to combustion of the fuel and oxygen-mixed gas with the BSS. Moreover, TSL process can easily remove the impurities that are generated through the formation of slag in the upper furnace (Bakker M.L. et al., 2011).

However, it is difficult to directly feed certain raw materials that are fine dusts to a TSL furnace because of dust-scattering during the injection step. To solve this problem, the density of the BSS can be increased during the reduction process using a fluidized bed reactor. This is done in a stage prior to the TSL furnace, and can be effective for increasing process throughput. The reduction rate and reaction mechanism of BSS are very complex to determine because such slags can contain mixtures of copper, zinc, and various elements. Therefore, further research into the thermodynamics and reaction kinetics of BSS recovery processes is necessary to optimize process conditions in fluidized bed reactors.

The aim of this work is to determine the activation energy and reaction mechanism of BSS reduction by applying a pyro-metallurgical method using different reduction gas. Firstly, different parameters affecting the reduction ratio, such as reduction temperature and reduction time, were investigated. Then, based on the results of the reduction, the activation energy and reaction mechanism of BSS were determined using the Arrhenius equation (Igor I. K., 2008).

\section{Experimental}

The BSS that was used in this experimental was taken from the brass smelter of SEOWON CO. LTD in South Korea. The BSS sample was analyzed by inductively coupled plasma-atomic emission spectrometry (ICP-AES, ARL 3410, Switzerland) and X-ray diffraction (XRD, Siemens D-5000, Germany). The carbon concentration of the BSS sample was determined by an automatic elemental analyzer (AEA, Flash EA 1112 series, Thermo Fisher Scientific, U.S.A.). The extent of reduction of the BSS sample was estimated by a simultaneous thermogravimetric analyzer (TGA, TA SDT model 2060, TA Instruments, U.S.A.), under a flow of $5 \% \mathrm{H}_{2}+95 \% \mathrm{~N}_{2}$, at a flow rate $100 \mathrm{~cm}^{3} / \mathrm{min}$. The sample was heated to $850^{\circ} \mathrm{C}$ at a heating rate of $5^{\circ} \mathrm{C} / \mathrm{min}$.

The reduction of the BSS sample was carried out under a hydrogen atmosphere in a horizontal alumina tube furnace. The hydrogen flow rate was fixed at $100 \mathrm{~cm}^{3} / \mathrm{min}$ in all experiments. The respective effects of reduction tem- perature and time on the reaction rates of the brass secondary slags were investigated. Specifically, the reduction temperature was varied from 900 to $1050{ }^{\circ} \mathrm{C}$, and the reduction time was varied from 10 to $480 \mathrm{~min}$. Each sample of BSS, weighing $15 \mathrm{~g}$, was placed in an alumina crucible and then put in the tube furnace. Then, the samples were heated to the desired reduction temperature at a heating rate of $5^{\circ} \mathrm{C} / \mathrm{min}$. Finally, the samples were cooled in the furnace.

After reduction, phase analysis of the reduction products was performed by X-ray diffraction, using $\mathrm{Cu} K \alpha$ radiation $(40 \mathrm{kV}, 30 \mathrm{~mA})$ at step size increments of $0.1^{\circ}$. The microstructures of the reduction samples were observed using a field emission scanning electron microscopy (FE-SEM, JSM 6330F, Jeol, Japan). The respective chemical compositions of copper and zinc were analyzed using energy-dispersive X-ray spectroscopy (EDS, INCA, Oxford, U.K.).

\section{Results and discussion}

\subsection{Characteristic of BSS}

The chemical composition of the BSS sample used in this study is presented in Table 1, as determined by ICPAES and AEA. $\mathrm{ZnO}$ and $\mathrm{CuO}$ were identified by X-ray diffraction analysis as major components in the BSS, whereas $\mathrm{Zn}$-spinel $\left(\mathrm{ZnO} \cdot \mathrm{Al}_{2} \mathrm{O}_{3}\right)$ and $\mathrm{Al}_{2} \mathrm{SiO}_{4}$ were detected as a minor component, as shown in Fig. 1. Fig. 2a shows all the morphological features of the initial BSS sample. The latter consisted mainly of well-distinguishable, submicron-sized $\mathrm{ZnO}$ particles (Fig. 2b). The BSS samples were also leached with $\mathrm{HNO}_{3}+\mathrm{HCl}(3 \mathrm{M}: 1 \mathrm{M})$ to measure the other impurities. Bright particles indicate aluminum and silicon compounds, whereas other particles indicate silicon dioxide (Figs. 2c, d).

The thermogravimetric curve of the reduction process, which was recorded during a linear program at a constant heating rate, is shown in Fig. 3. As shown in Fig. 3, the TGA curve of the initial sample reveals two major weight losses: one has a monotonous weight decrease of $1.3 \%$ in the range of $50-760{ }^{\circ} \mathrm{C}$, and the other is very rapid and occurs at $760{ }^{\circ} \mathrm{C}$ with approximately $1.4 \%$ weight loss. The first weight loss is possibly related to the combustion of impurities, evaporation of water, and a chemical reaction between carbon in the BSS sample $(2.2$ mass\% in

Table 1 Chemical composition of the initial brass secondary slags (mass \%)

\begin{tabular}{ccccccccc}
\hline $\mathrm{Cu}$ & $\mathrm{Zn}$ & $\mathrm{Si}$ & $\mathrm{Al}$ & $\mathrm{Pb}$ & $\mathrm{Fe}$ & $\mathrm{Mn}$ & $\mathrm{C}$ & Other \\
\hline 14.74 & 70.54 & 3.92 & 5.7 & 1.01 & 0.74 & 0.32 & 2.2 & 0.83 \\
\hline
\end{tabular}




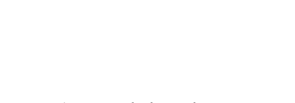

Table 19 and hydrogen gas. The other weight loss (1.4\%) isverue to the reduction of zinc oxide in the BSS sample to zinc gas phase, by hydrogen gas (Gioia F. et al., 1977).

\subsection{Reduction mechanism of BSS}

Fig. 4 shows the XRD patterns of BSS samples prior to and after reduction at various temperatures $\left(900-1050{ }^{\circ} \mathrm{C}\right)$ for varying reaction times (10-480 min). Generally, XRD patterns for reductions at the four temperatures are similar, with the exception of time-scale, indicating that the same reduction mechanism prevails in the range of 900$1050{ }^{\circ} \mathrm{C}$. These results suggest a stepwise reduction

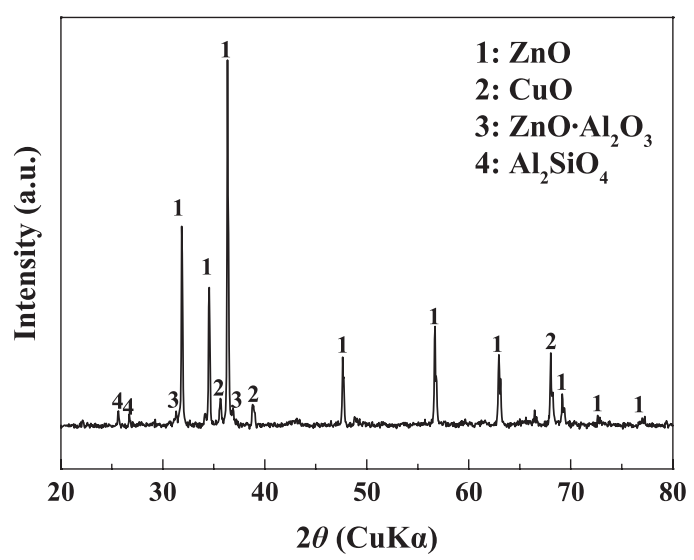

Fig. 1 X-ray diffraction pattern of initial BSS sample. mechanism of BSS with hydrogen gas. Thus, based on these XRD results, a two-step reaction was identified. The main reactions at each step are as follows: Step 1 is the $\mathrm{ZnO}$ reduction (Eqn. 1), and step 2 is the $\mathrm{ZnO} \cdot \mathrm{Al}_{2} \mathrm{O}_{3}$ reduction (Eqn.2).

$$
\begin{aligned}
& \mathrm{ZnO}(\mathrm{s})+\mathrm{H}_{2}(\mathrm{~g}) \rightarrow \mathrm{Zn}(\mathrm{g})+\mathrm{H}_{2} \mathrm{O}(\mathrm{g}) \\
& \mathrm{ZnO} \cdot \mathrm{Al}_{2} \mathrm{O}_{3}(\mathrm{~s})+\mathrm{H}_{2}(\mathrm{~g}) \rightarrow \mathrm{Zn}(\mathrm{g})+\mathrm{Al}_{2} \mathrm{O}_{3}(\mathrm{~s})+\mathrm{H}_{2} \mathrm{O}(\mathrm{g})
\end{aligned}
$$

The morphology changes in the BSS samples versus the reduction times at $1050{ }^{\circ} \mathrm{C}$ are shown in Fig. 5. It is seen that the initial fine $\mathrm{ZnO}$ powder is aggregated at the

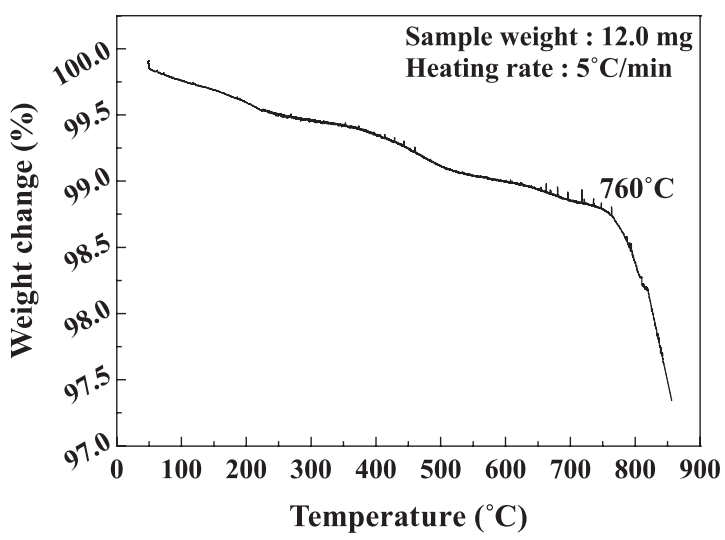

Fig. 3 TGA analysis of the BSS sample in mixed gas $(5 \%$ $\mathrm{H}_{2}+95 \% \mathrm{~N}_{2}$ ).
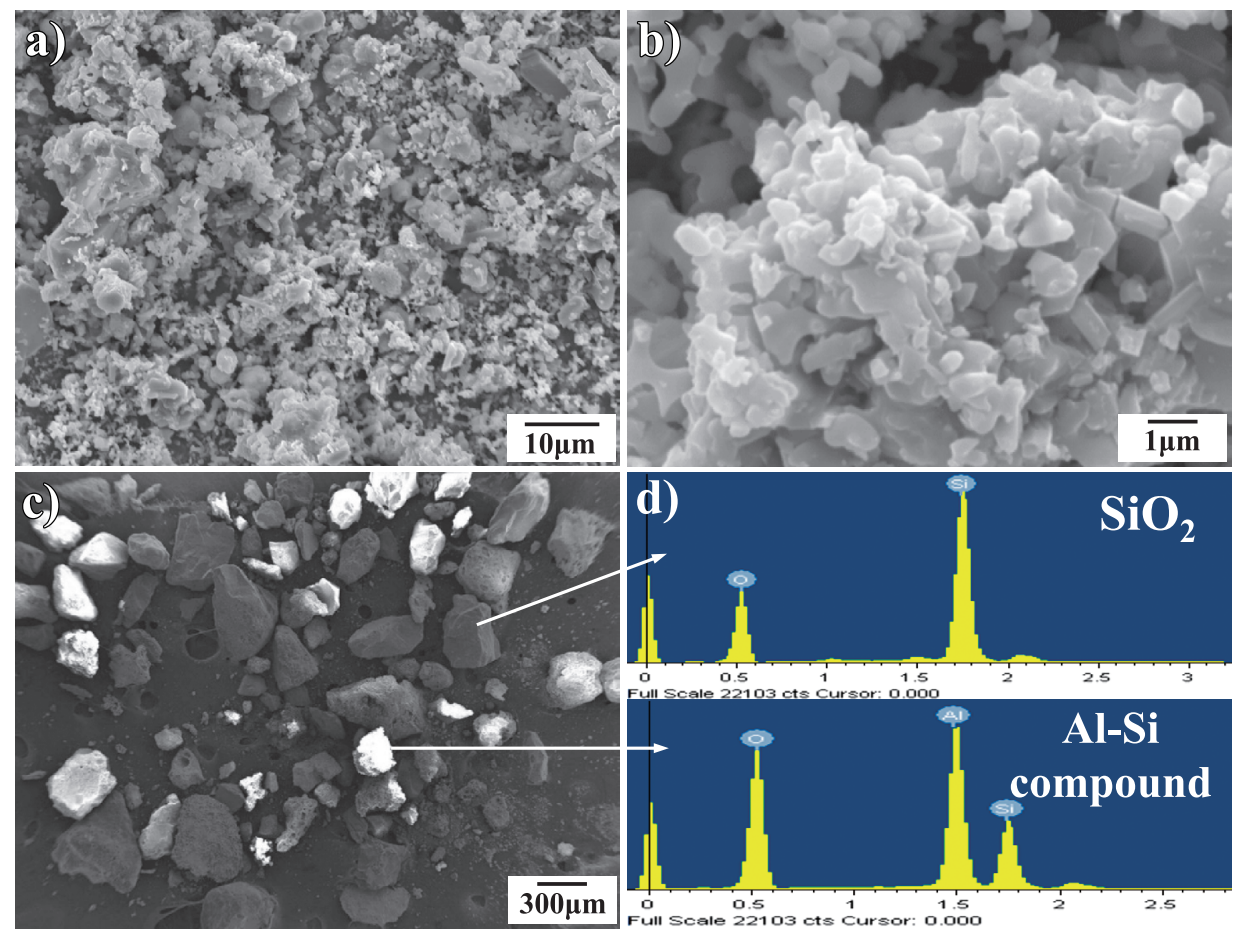

Fig. 2 SEM morphologies of BSS samples: a) whole morphological features of the initial samples, b) the submicron-size $\mathrm{ZnO}, \mathrm{c}$ ) after $\mathrm{ZnO}$ leaching with $\mathrm{HCl}+\mathrm{HNO}_{3}$, and d) $\mathrm{EDS}$ analysis results. 


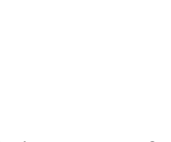

joutial stage of the reaction, after which the $\left[\mathrm{ZnO} \cdot \mathrm{Al}_{2} \mathrm{O}_{3} /\right.$ Cul] mixture forms a more dense structure as shown in Figs. 5a, b, respectively. The amount of $\mathrm{ZnO}$ powder decreased with increasing reduction time because $\mathrm{Zn}$ evaporated after reduction by hydrogen gas according to Eqn. 1. Also, it should be noted that $\mathrm{Cu}$ powder, having spherical particles of $\sim 1 \mu \mathrm{m}$, appeared after removal of the $\mathrm{ZnO}$ at $120 \mathrm{~min}$ of the reaction time. Furthermore, there was no significant change in the shape or particle size of the $\mathrm{Cu}$ particles, even after $480 \mathrm{~min}$.

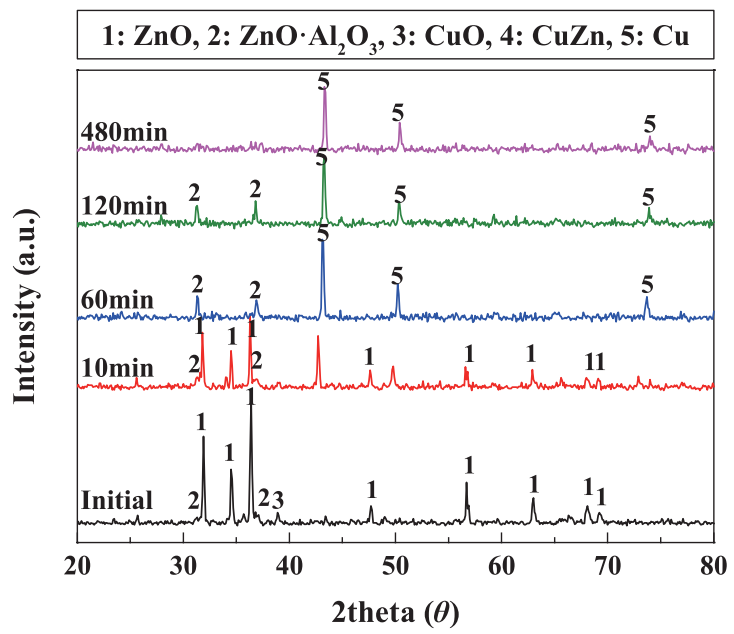

Fig. 4 XRD patterns of BSS, prior to, and after, hydrogen reduction at $1000{ }^{\circ} \mathrm{C}$ for various times.
The distilled $\mathrm{Zn}$ was recovered as metallic $\mathrm{Zn}$ in the cold zone of the alumina tube, as shown in the inset of Fig. 6a. In the cold zone, it was condensed and formed $\mathrm{Zn}$ powder immediately. The latter had spherical particles with a size range of approximately $1-6 \mu \mathrm{m}$. The XRD pattern confirms that the recovered powder is composed of pure $\mathrm{Zn}$, without any other components. This is due to much difference in evaporation temperature between $\mathrm{Zn}$ $\left(907^{\circ} \mathrm{C}\right)$ and $\mathrm{Cu}\left(2562{ }^{\circ} \mathrm{C}\right), \mathrm{SiO}_{2}\left(2950^{\circ} \mathrm{C}\right), \mathrm{Al}_{2} \mathrm{O}_{3}$ $\left(2977^{\circ} \mathrm{C}\right)$ and $\mathrm{CuO}\left(2000^{\circ} \mathrm{C}\right)$, respectively.

From the XRD and SEM data, the process of $\mathrm{Cu}$ reduction from BSS comprises several stages. The first step is the conversion of brass to $\mathrm{Cu}$ with distilled $\mathrm{Zn}$. According to previous research, the brass is generated by the reaction of $\mathrm{CuO}$ and $\mathrm{ZnO}$ with hydrogen gas at above $600{ }^{\circ} \mathrm{C}$ (Kappenstein C. et al., 1996). The concentration of $\mathrm{Zn}$ in brass decreased with increasing reduction temperature and times. This was due to loss of $\mathrm{Zn}$ by distillation from the brass during the first step. Fig. 7 shows the respective concentrations of $\mathrm{Cu}$ and $\mathrm{Zn}$ in brass as a function of reduction temperature and reaction time. Here, $\mathrm{Cu}$ concentration increases with reduction time; moreover, the rate of increase of $\mathrm{Cu}$ concentration is reduced with decreasing reduction temperature as shown in Fig. 7a.

The $\mathrm{Cu}$ concentration increase is attributed to not only reduction of $\mathrm{CuO}$ but also evaporation of reduced $\mathrm{Zn}$. The contribution of $\mathrm{Zn}$ is presented in Fig. $\mathbf{7 b}$, where $\mathrm{Zn}$ concentration linearly decreases in the early of the reaction time at most of the reduction temperature. In the case of
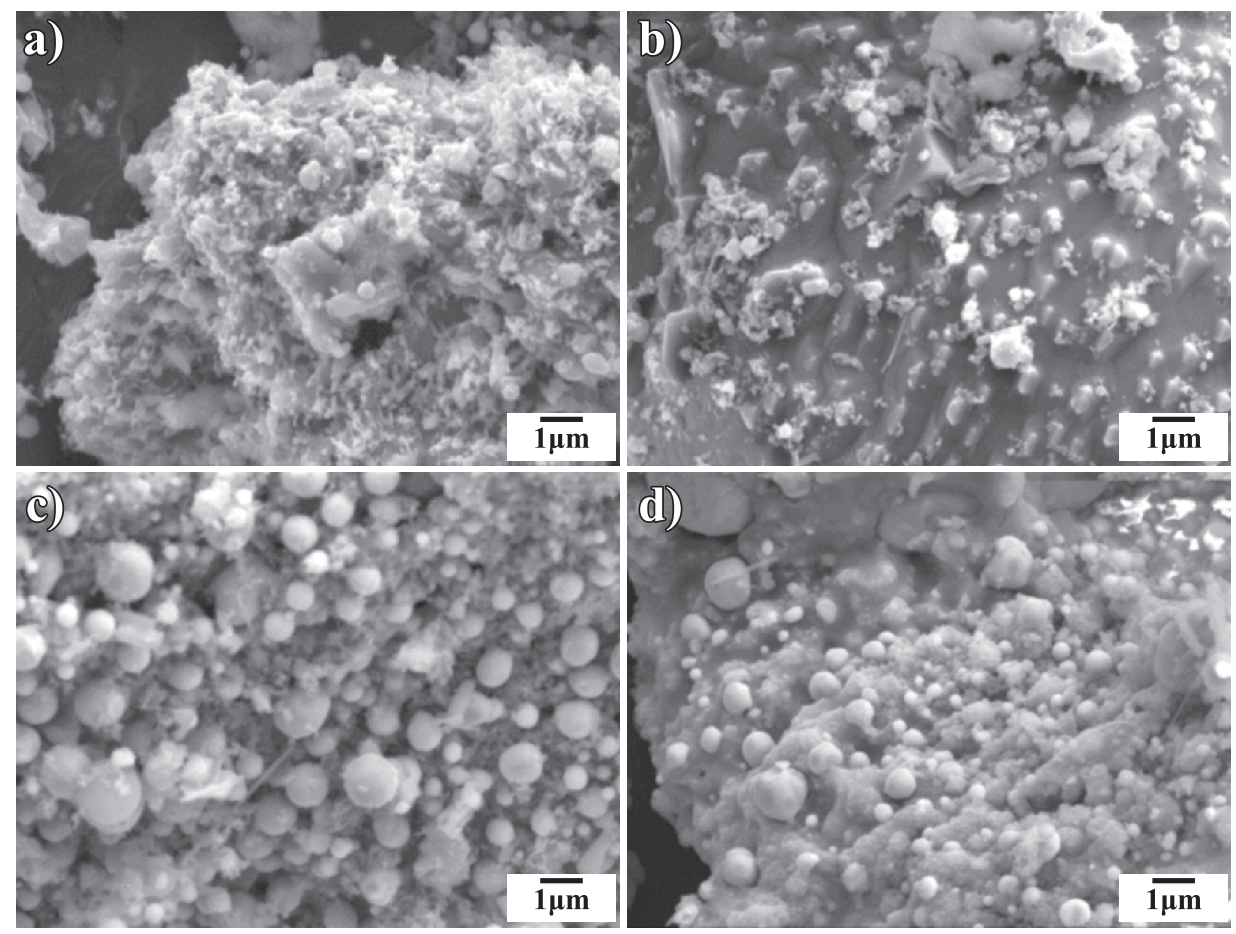

Fig. 5 The morphology change in BSS versus hydrogen reduction times at $1050^{\circ} \mathrm{C}:$ a) 10 , b) 60 , c) 120 , and d) $480 \mathrm{~min}$. 

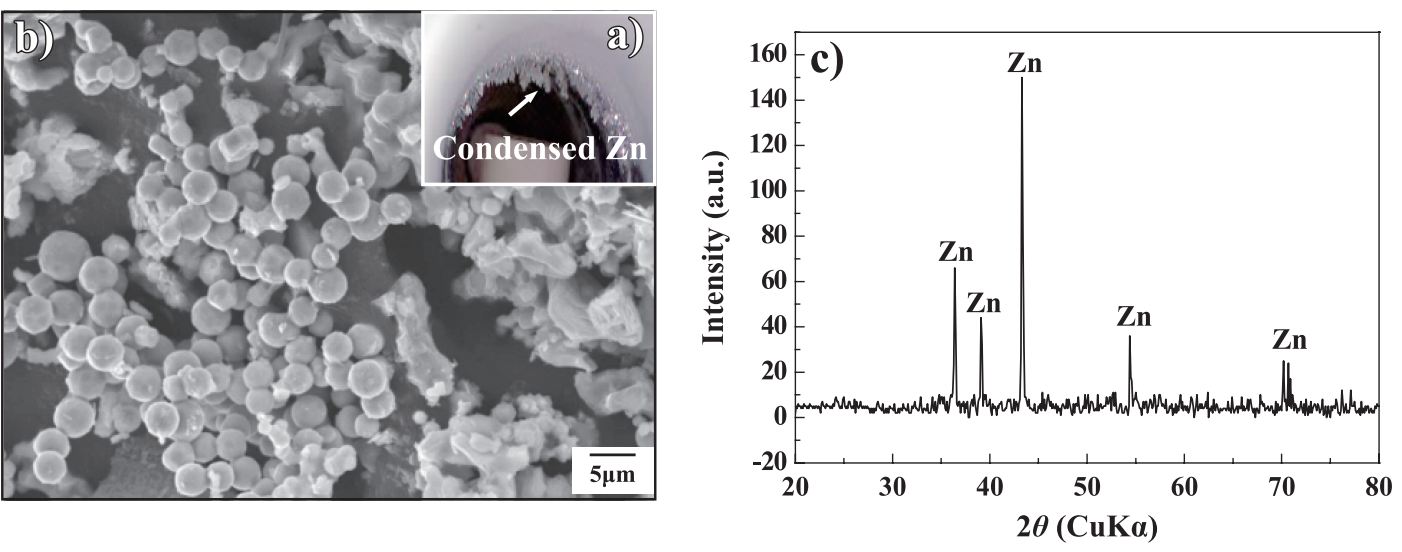

Fig. 6 a) Metal zinc powders recovered from $\mathrm{ZnO}$ in BSS at the cold zone of furnace, b) morphology of metal $\mathrm{Zn}$ powder, and c) XRD pattern of metal $\mathrm{Zn}$ powder.

reactions performed at $1000{ }^{\circ} \mathrm{C}$ and $1050{ }^{\circ} \mathrm{C}$, all $\mathrm{Zn}$ is eliminated by $480 \mathrm{~min}$ and $360 \mathrm{~min}$, respectively. Lastly, a significant amount of $\mathrm{Zn}$ remained in the $\mathrm{Cu}$ phase at $900{ }^{\circ} \mathrm{C}$ for all reduction times.

\subsection{The kinetics analysis of BSS}

In order to understand the reduction mechanism for BSS, a series of kinetic analyses were performed. For this, the extent of BSS reduction was integrated with respect to time and plotted cumulatively as a reaction ratio $(\alpha)$. The reaction ratio was defined as 0 before the reaction and 1 when it was completed. The rate of each reaction was expressed as a function of Arrhenius parameters with reaction model in Eqn. 3:

$$
\mathrm{d} \alpha / \mathrm{d} t=k(T) f(\alpha)
$$

where $\mathrm{d} \alpha / \mathrm{d} t$ is the reaction rate, $\alpha$ the reaction ratio, $k(T)$ is the temperature-dependent rate constant, $t$ is the time, $T$ is temperature, and $f(\alpha)$ is the differential form of the reaction model (Santosh K.U., 2006). We used the first-order reaction model $f(\alpha)=1-\alpha$ for this reaction. This model is applicable to a wide range of solid-state reactions: Reactant(s) $\rightarrow$ Product(s) + Gas (g) (James E.H., 2007). For the purpose of this kinetic analysis, the residual mass at various reduction times was expressed as the reaction ratio $(\alpha)$, by means of Eqn. 4 :

$$
\alpha=\left(M_{0}-M_{\mathrm{t}}\right) / M_{0}
$$

where $M_{\mathrm{t}}$ represents the mass of the sample at a reduction time $t$ and $M_{0}$ is the initial mass of the sample. Therefore, a more general form of the first-order reaction equation can be written as follows:

$$
-\ln (1-\alpha)=k(T) t
$$
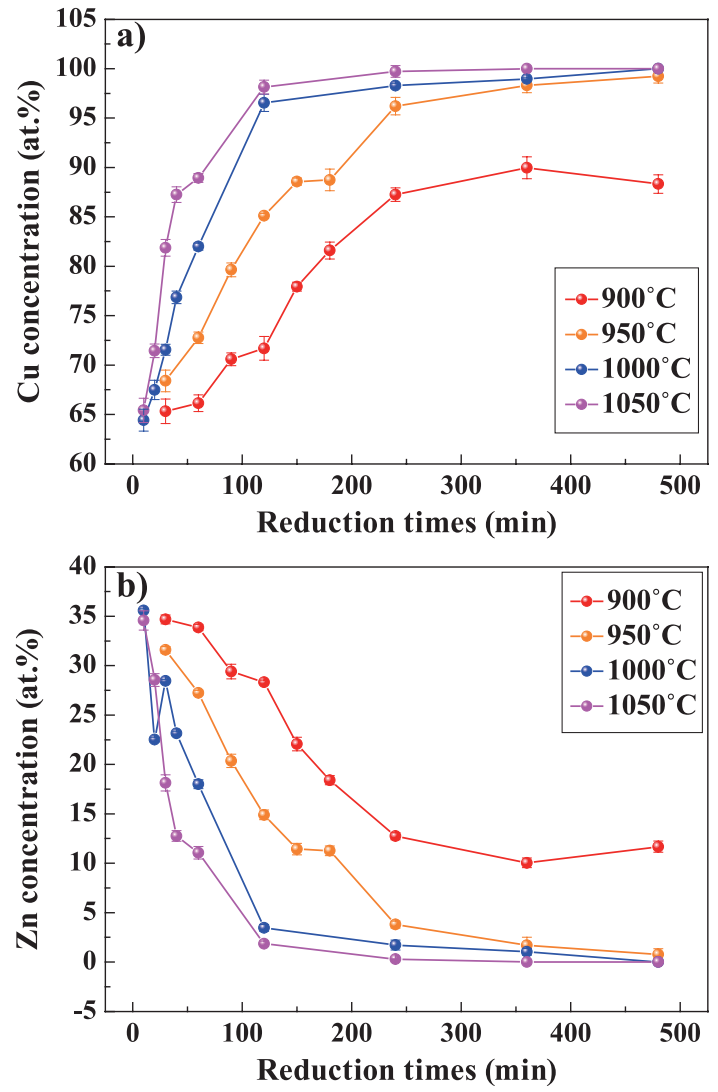

Fig. 7 Concentration change of $\mathrm{Cu}$ and $\mathrm{Zn}$ in brass by $\mathrm{Zn}$ vaporization according to reduction times and temperature: a) $\mathrm{Cu}$, and b) $\mathrm{Zn}$.

Thus, by plotting $-\ln (1-\alpha)$ versus $t$, the rate constant $(k)$ can be determined from the slope and intercept of the fitted straight line. Values for the rate constant $(k)$ calculated for $\alpha$, in the range $0.2-1$, are given in Table 2. The transformation step 2 is not as rapid as step 1, although the amount of $\mathrm{ZnO} \cdot \mathrm{Al}_{2} \mathrm{O}_{3}$ is relative small. Specifically, the rate constant of step 1 increases from $1.4 \pm 0.13 \times 10^{-3} \mathrm{~s}^{-1}$ at $900^{\circ} \mathrm{C}$ to $2.18 \pm 0.15 \times 10^{-2} \mathrm{~s}^{-1}$ at $1050^{\circ} \mathrm{C}$. Meanwhile, the rate constant of step 2 increases from $1.54 \pm 0.21 \times 10^{-5} \mathrm{~s}^{-1}$ at 
Table 2 Summary of rate constants $k$ of BSS sample reduction at different temperature and step

\begin{tabular}{ccc}
\hline & STEP 1 $\left(\mathrm{s}^{-1}\right)$ & STEP 2 $\left(\mathrm{s}^{-1}\right)$ \\
\hline $900{ }^{\circ} \mathrm{C}$ & $1.4 \pm 0.13 \times 10^{-3}$ & $1.54 \pm 0.21 \times 10^{-5}$ \\
$950{ }^{\circ} \mathrm{C}$ & $5.52 \pm 0.72 \times 10^{-3}$ & $5.61 \pm 0.68 \times 10^{-5}$ \\
$1000^{\circ} \mathrm{C}$ & $1.16 \pm 0.24 \times 10^{-2}$ & $3.45 \pm 0.52 \times 10^{-4}$ \\
$1050{ }^{\circ} \mathrm{C}$ & $2.18 \pm 0.15 \times 10^{-2}$ & $1.09 \pm 0.19 \times 10^{-3}$ \\
\hline
\end{tabular}

$900{ }^{\circ} \mathrm{C}$ to $1.09 \pm 0.19 \times 10^{-3} \mathrm{~s}^{-1}$ at $1050{ }^{\circ} \mathrm{C}$. The temperaturedependence of the rate constant is traditionally described by the Arrhenius law:

$$
k(T)=A \exp -\left(E_{\mathrm{a}} / R T\right)
$$

In Eqn. 6, $A$ is the pre-exponential factor, $E$ is the activation energy, and $R$ is the universal gas constant. Rewriting Eqn. 6 (Jelic D. et al. 2011),

$$
\ln k=\ln k-\left(E_{\mathrm{a}} / R T\right)
$$

The activation energies $\left(E_{\mathrm{a}}\right)$ calculated for steps 1 and 2 are $233.2 \pm 26.1$ and $376.7 \pm 22.4 \mathrm{~kJ} / \mathrm{mol}$, respectively, as shown in Fig. 8. The significant coefficients of determination $\left(R^{2}\right)$ of the activation energy indicated 0.963 and 0.989 as confidence level, respectively. The reaction mechanism, deduced from the kinetic data, is depicted graphically as shown in Fig. 9. In step 1, the reductions of $\mathrm{CuO}$ and $\mathrm{ZnO}$ begin at $500{ }^{\circ} \mathrm{C}$ and $600{ }^{\circ} \mathrm{C}$, respectively. $\mathrm{ZnO}$ starts to evaporate as soon as it is reduced to the metallic phase, due to its high vapor pressure, and this evaporation is the main cause of the weight loss in this reaction system. In the temperature up to $600^{\circ} \mathrm{C}, \mathrm{Cu}$ forms a brass phase with $\mathrm{Zn}$, whereas the brass phase decomposes into solid $\mathrm{Cu}$ and $\mathrm{Zn}$ vapor at $900{ }^{\circ} \mathrm{C}$, which is step 2. It should be noted that $\mathrm{ZnO}$ in the $\mathrm{ZnO} \cdot \mathrm{Al}_{2} \mathrm{O}_{3}$ spinel phase is also reduced in this step; hence, $\mathrm{Cu}, \mathrm{SiO}_{2}$, and $\mathrm{Al}_{2} \mathrm{O}_{3}$ are the final phase formed in this BSS reduction system. It is supposed that the ceramic impurities are removed by the succeeding smelting process.

\section{Conclusion}

The reduction kinetics of BSS in a hydrogen atmosphere has been studied at $900^{\circ} \mathrm{C}$ to $1050{ }^{\circ} \mathrm{C}$, and for the reduction times between $10 \mathrm{~min}$ and $480 \mathrm{~min}$. The characterization of the samples was done by means of SEM and XRD analysis. The results indicated that the reduction of BSS samples was found to occur in a two-step process, with recovery of $\mathrm{Zn}$ powder (spherical particles, size: approximately $1 \sim 6 \mu \mathrm{m})$. The first step involved a rapid transformation of $\mathrm{ZnO}$ to $\mathrm{Zn}(\mathrm{g})$, whereas the sec-
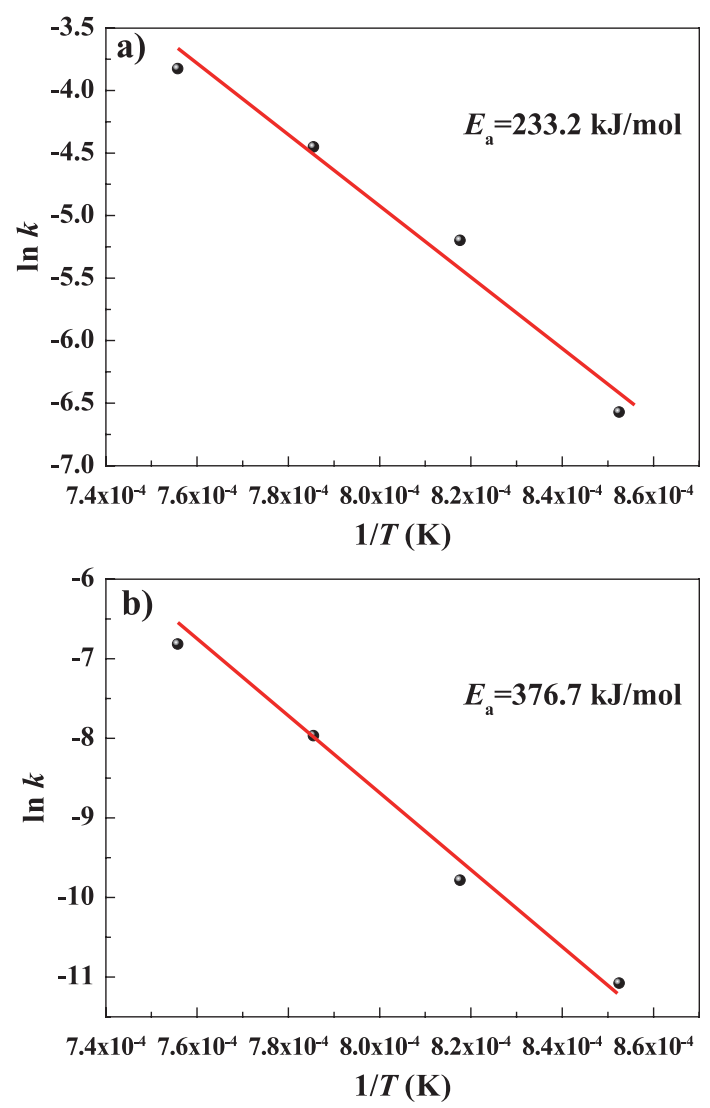

Fig. 8 Arrhenius plot for the dominant reaction in the range of 900-1050 ${ }^{\circ} \mathrm{C}$ with hydrogen gas: a) step 1 ( $\mathrm{ZnO}$ reduction); and b) step $2\left(\mathrm{ZnO} \cdot \mathrm{Al}_{2} \mathrm{O}_{3}\right.$ reduction).

ond step involved the slow conversion from $\mathrm{ZnO} \cdot \mathrm{Al}_{2} \mathrm{O}_{3}$ to $\mathrm{Zn}$ (g).

A first-order function and Arrhenius analysis were utilized to calculate the rate constants and activation energies for the BSS reduction. In particular, the rate constant for the transformation from $\mathrm{ZnO}$ to $\mathrm{Zn}(\mathrm{g})$ increased from $1.4 \pm 0.13 \times 10^{-3} \mathrm{~s}^{-1}$ at $900{ }^{\circ} \mathrm{C}$ to $2.18 \pm 0.15 \times 10^{-2} \mathrm{~s}^{-1}$ at $1050{ }^{\circ} \mathrm{C}$ with an activation energy of $233.2 \pm 26.1 \mathrm{~kJ} / \mathrm{mol}$ in step 1 . In step 2 , the corresponding rate constant for the transformation from $\mathrm{ZnO} \cdot \mathrm{Al}_{2} \mathrm{O}_{3}$ to $\mathrm{Zn}(\mathrm{g})$ increased from $1.54 \pm 0.21 \times 10^{-5} \mathrm{~s}^{-1}$ at $900{ }^{\circ} \mathrm{C}$ to $1.09 \pm 0.19 \times 10^{-3} \mathrm{~s}^{-1}$ at $1050^{\circ} \mathrm{C}$ with an activation energy of $376.7 \pm 22.4 \mathrm{~kJ} / \mathrm{mol}$. It is believed that further understanding of the reaction mechanism observed in this study can contribute to the further optimization of process conditions in fluidized bed reactors.

\section{Acknowledgements}

This research was supported by a grant from the Fundamental R \& D Program for Energy (No. 2012T100100092, ("Development of pyrometallurgical technology for low quality urban mining by-products") funded by the Ministry of Knowledge Economy, Republic of Korea. 

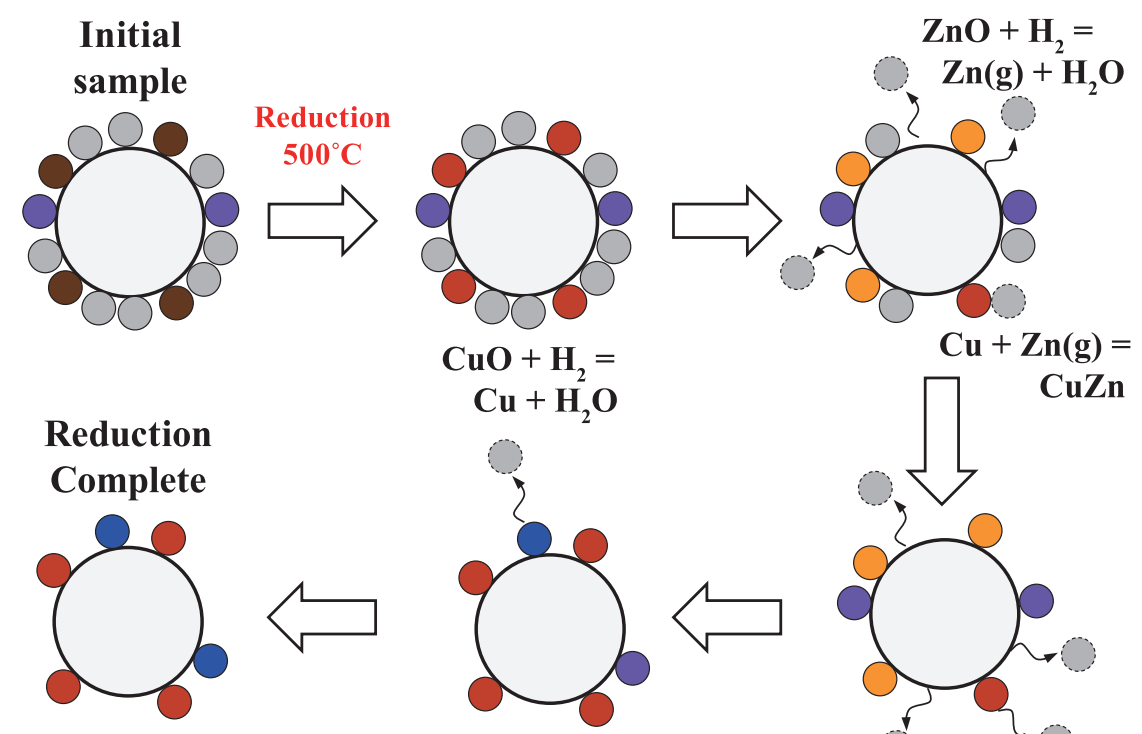

$$
\begin{array}{r}
\mathrm{CuO}+\mathrm{H}_{2}= \\
\mathrm{Cu}+\mathrm{H}_{2} \mathrm{O}
\end{array}
$$
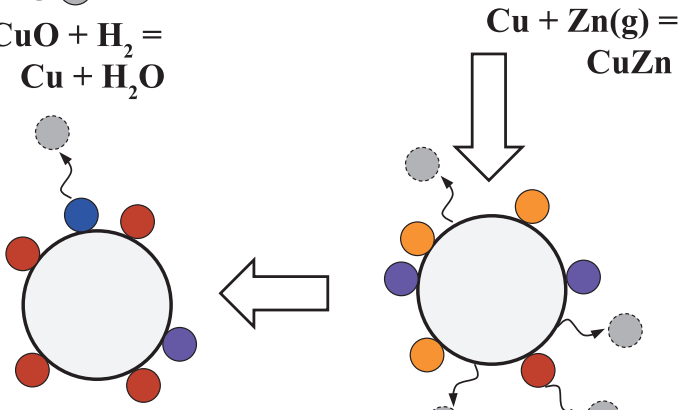

$\mathrm{ZnOAl}_{2} \mathrm{O}_{3}+\mathrm{H}_{2}=$ $\mathrm{Zn}(\mathrm{g})+\mathrm{Al}_{2} \mathrm{O}_{3}+\mathrm{H}_{2} \mathrm{O}$

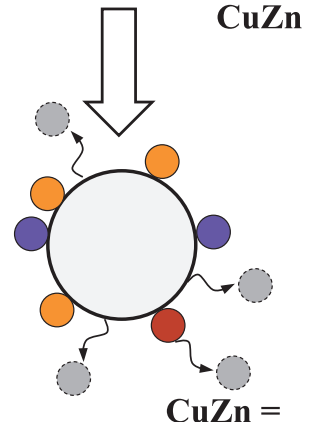

$\mathrm{Cu}+\mathrm{Zn}(\mathrm{g})$

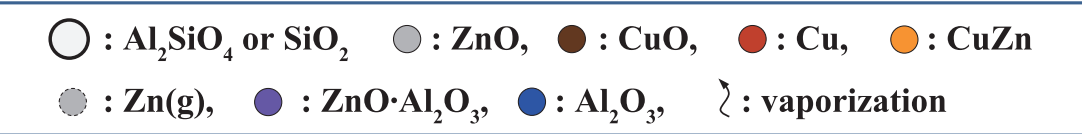

Fig. 9 Schematic diagram of BSS samples reduction mechanism between room temperature and $1050{ }^{\circ} \mathrm{C}$ with hydrogen gas.

\section{References}

Altundogan H.S., Tumen F., Metal recovery from copper converter slag by roasting with ferric sulphate, Hydrometallurgy, 44 (1997) 261-267.

Anand S., Kanta R.P., Jena P.K., Recovery of metal values from copper converter and smelter slags by ferric chloride leaching, Hydrometallurgy, 5 (1980) 355-365.

Anand S., Sarveswara R.K., Jena P.K., Pressure leaching of copper converter slags using dilute sulphuric acid for the extraction of cobalt, nickel and copper values, Hydrometallurgy, 67 (1983) 1-7.

Bakker M.L., Nikolic S., Mackey P.J., ISASMELT ${ }^{\mathrm{TM}}$-Application for nickel, Minerals Engineering, 24 (2011) 610-619.

Gioia F., Mura G., Viola A., Experimental study of the direct reduction of sinterized zinc oxide by hydrogen, Chemical Engineering Science, 33 (1977) 1401-1409.

Gorai B., Jana R.K. Premchand, Characteristics and utilisation of copper slag-a review, Resources conservation and recycling, 39 (2003) 299-313.

Igor I. Katkov, Challenge from the simple: Some caveats in linearization of the Boyle-van't Hoff and Arrhenius plots, Cryobiology, 57 (2008) 142-149.

James E.H., Principles of chemical kinetics $2^{\text {nd }}$ eds., Academic Press, New York, 2007.

Jelic D., Tomic-Tucakovic B., Mentus S., A kinetic study of copper oxide powder reduction with hydrogen, based on thermogravimetry, Thermochimica Acta, 521 (2011) 211217.

Jha M.K., Kumar V., Singh R.J., Review of hydro-metallurgical recovery of zinc from industrial wastes, Resources conservation and recycling, 33 (2001) 1-22.

Kappenstein C., Cernak H., Brahmi R., Duprez D., Chomic J., Copper-zinc oxide catalysts. Part IV. Thermal treatment in air, argon and hydrogen and XRD study of new bimetallic precursors-direct formation of alloys, Thermochimica Acta, 279 (1996) 65-76.

Moskalyk P.R., Alfantazi A.M., Review of copper pyrometallurgical practice: today and tomorrow, Minerals Engineering, 16 (2003) 893-919.

Rudnik E., Burzynska L., Gumoska W., Hydrometallurgical recovery of copper and cobalt from reduction-roasted copper converter slag, Minerals Engineering, 22 (2009) 88-95.

Santosh K.U., Chemical kinetics and reaction dynamics, Springer, New Delhi, 2006.

Sharma K.D. and Row B.R.K., An electrolytic process for recovery of zinc dust from melting furnace slag, Hydrometallurgy, 13 (1985) 377-383.

Sukla L.B., Panda S.C., Jena P.K., Recovery of cobalt, nickel and copper from converter slag through roasting with ammonium sulphate and sulphuric acid, Hydrometallurgy, 16 (1986) 153-165. 


\section{Author's short biography}
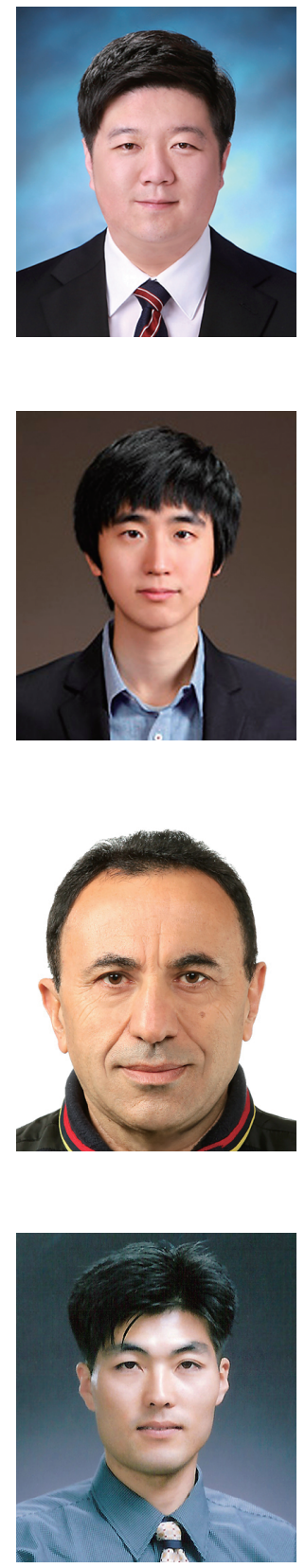

\section{Tae-Hyuk Lee}

Tae-Hyuk Lee is a doctor candidate for Materials Engineering, Chungnam National University, South Korea. He received his M.D. from Chungnam National University, South Korea in 2012. He is now pursuing his Ph.D. in Chungnam National University focusing on stress corrosion cracking of Inconel 690 for steam generator tubes. His research interests include stress corrosion cracking, recycling of metals, and metal matrix composites.

\section{Sin-Hyeong Joo}

Sin-Hyeong Lee is a master's course for Materials Engineering, Chungnam National University, South Korea. He received his B.S. from Chungnam National University, South Korea. His research interests include powder metallurgy materials and processing, in particular non-ferrous materials, such as boron, boron composite, silver and silicon.

\section{Hayk H Nersisyan}

Hayk Nersisyan is research professor of Materials Science \& Engineering at Chungnam National University in South Korea and Rapidly Solidified Materials Research Center. He received his B.S., M.S. and Ph D degrees from Yerevan State University in Armenia. His major research field is powder metallurgy materials and processing, in particular non-ferrous materials and their composites such as magnesium, titanium, aluminium and copper.

\section{Man-Sik Kong}

Man-Sik Kong is senior researcher of Plant Engineering Center, Institute for Advanced Engineering, South Korea. He received his B.S., and M.S degree from Gyeongsang National University and Ph D. degree from Ajou University in South Korea. Dr. Kong's research interests include powder metallurgy materials, processing and recycling of rare metals. 


\section{Author's short biography}

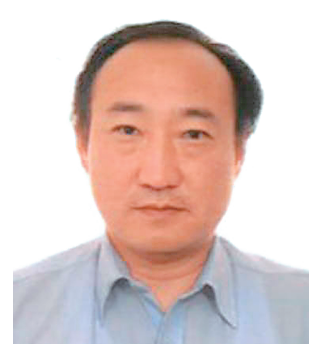

\section{Jae-Woo Lee}

Jae-Woo Lee is director of SEWON CO., LTD, South Korea. He received his B.S. degree from Hanyang University in South Korea. His research interests include recycling process of copper and copper alloy, recovery of metals from urban mine.

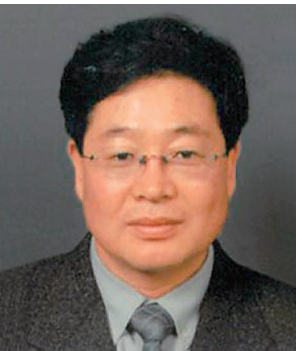

\section{Ki-Won Park}

Ki-Won Park is head of research center of SEWON CO., LTD, South Korea. He received his B.S. degree from Inha University in South Korea. His research interests include recycling process of copper and copper alloy, recovery of metals from urban mine.

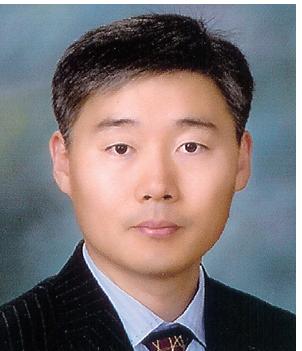

\section{Jong-Hyeon Lee}

Jong-Hyeon Lee is Professor in Department of Materials Science \& Engineering at Chungnam National University in South Korea and head of Rapidly Solidified Materials Research Center. He received his B.S., M.S, and Ph D degrees from Chungnam National University. His major research field is electro refining, winning, and coating of rare metals. He also studies on powder synthesis by self-propagating high temperature synthesis. He published more than 100 articles and 30 patents. 